\title{
Espacio e identidad: narradores del norte de México
}

\author{
ALICIA LLARENA*
}

Resumen:

En una civilización que, como la nuestra, se ha erigido sobre los pilares del lenguaje y del discurso, la función del espacio literario es esencial. No sólo porque nuestra imagen del mundo depende de las representaciones que se han ido fraguando a través de la semántica, sino porque el espacio es, además, la categoría más importante e interdisciplinaria de cuantas configuran nuestro sistema cultural.

Desde esta perspectiva puede apreciarse la importancia del espacio literario en la expresión identitaria de América Latina y, especialmente, en algunos de sus más recientes "regionalismos" narrativos, entre los cuales los llamados "Narradores del Norte de México" tienen un lugar destacado, en tanto fundadores de una tradición regional que acentúa en la escritura la presencia de sus singulares accidentes geográficos y que visibiliza la frontera como una región cultural específica, dotada de una personalidad histórica y sociológica que le confiere su propia identidad.

Palabras clave:

Espacio literario, narradores del Norte de México, literatura fronteriza, nuevos regionalismos, Luis Humberto Crosthwaite, Jesús Gardea.

En el ámbito literario la importancia del espacio no ha sido subrayada lo suficiente, sobre todo si lo comparamos con otros elementos

* Profesora-investigadora. Universidad de Las Palmas de Gran Canaria. 
del discurso, especialmente el punto de vista, el tiempo del relato o los propios personajes de la fábula. Sin embargo, una mirada más profunda y atenta a las funciones espaciales nos indicará enseguida su efecto mediador entre todas las instancias del relato y, por lo tanto, su rol protagónico. Si, además, contrastamos el papel del espacio a la luz de otras disciplinas (desde la antropología a la semiótica teatral, o desde la geografía y la filosofía hasta la arquitectura) será ya inevitable afirmar rotundamente su importancia como categoría cultural, subrayar su prioridad como fundamento de nuestra visión del mundo y nuestra percepción de la realidad y enfatizar su íntima vinculación con las representaciones identitarias, fenómeno singularmente apreciable en la historia literaria de Hispanoamérica, desde las crónicas de Indias hasta nuestros días. ${ }^{1}$

Por otro lado, es evidente que la aparición de recientes materiales bibliográficos o el advenimiento de nuevas corrientes de pensamiento en el circuito académico (la "ecocrítica", la "ecosofía" o el "ecofeminismo") junto a otros síntomas socio-culturales a los que luego aludiré, están dando cuenta de un fenómeno que a estas alturas no ofrece ya ninguna duda: que "el mundo actual en su actuar y en su pensar se nos está volviendo cada vez más 'espacialista"' (D'Ors 9). De hecho, en una disciplina tan estrechamente ligada al espacio como la Geografía, por ejemplo, este fenómeno aflora incluso en el lenguaje, como indica Peter Gould:

Pensamos en palabras, y las palabras reflejan nuestro pensamiento. Uno de los mayores cambios que se produjeron a finales de los 50 y principios de los 60 fue el uso adjetivo de la palabra "espacial" para lo que antes se podía haber llamado "geográfico". Se habla desde entonces de interacción espacial, organización espacial, estadística, relaciones, comportamiento, modelos, planificación, aplicaciones, patrones, difusión... y estructura espacial. (Gould 7)

${ }^{1}$ Las ideas y reflexiones esbozadas en este artículo forman parte de nuestro trabajo Espacio, identidad y literatura: el caso de Hispanoamérica, cuyos contenidos principales fueron expuestos públicamente en la Universidad de Las Palmas de Gran Canaria como proyecto de investigación en 2003. 
Merece la pena, pues, reflexionar siquiera brevemente sobre el espacio literario y sobre el rol que éste desempeña en una civilización que, como la nuestra, se erige sobre los pilares del lenguaje y de la representación, para asomarnos finalmente a un fenómeno atractivo y singular de la escritura mexicana contemporánea: la emergencia de los llamados "Narradores del Norte", nuevos escribanos de un territorio donde se han puesto en juego las jugosas cuestiones identitarias y los ricos y diversos cruzamientos del espacio fronterizo.

\section{La importancia del espacio: fundamentos culturales}

La pérdida de la referencia espacial parece evidente a la luz de las grandes masas migratorias que han cambiado el rostro de la tierra en las últimas décadas, prodigando el desplazamiento entre las naciones y los consiguientes desajustes entre identidad y territorio, hasta configurar una nueva sintomatología que algunos bautizan como el síndrome del "Anyplace", "The peculiarly modern malaise called placelessness" ("el mal peculiarmente moderno llamado sinespacio" [Lutwack 182-183]). Pero curiosamente -y esto es lo que me interesa subrayar aquí- el peso específico del espacio se ha vuelto mayor a medida que han crecido los procesos globalizadores, reavivando las interferencias entre lo local y lo global, que ya han quedado estigmatizadas en un nuevo término, la "glocalización".

Así, movilidad y desplazamiento, comunicación y exilio, internacionalización e itinerancia, no han conseguido restar presencia a regiones y provincias, sino al contrario, las han dotado de un relieve especial, afirmando la importancia del territorio, como sugieren las modas étnicas, el énfasis ecológico e incluso los intereses de la nueva geografía, atenta hoy como nunca a los efectos sociales del espacio más inmediato: "En la medida en que se conoce el territorio -apunta Villanueva Zarazaga- se ayuda a comprender temas y problemas, algunos recurrentes y en la actualidad candentes, como los nacionalismos, la identidad territorial, los temas de conflictos fronterizos y movimientos irredentistas, y la ordenación territorial en sî" (Villanueva 2). 
Al mismo tiempo, humanistas como Alain Finkielkraut recuperan ahora el concepto de "arraigo" esbozado en su día por Simone Weil en Echar raíces (1943), un libro que Albert Camus, su editor, consideró entonces como un auténtico tratado de civilización y donde la filósofa advirtiera que "El arraigo es quizás la necesidad más importante y la más desconocida del alma humana" (Weil 51). Al hilo de esta idea, Finkielkraut señalará que "En la época moderna, la técnica nos ha permitido desligarnos de la tierra, hoy en día, creo que debemos desligarnos de la técnica para conservar cierto contacto con la tierra" (Rapin), y que urge en nuestros días desligarse de los prejuicios de la globalización, evitando los efectos de una peligrosa disyunción entre lo particular y lo universal: "El mundo no es forzosamente lo que nos dice esta forma de la mundialización, ni sólo redes. Es también territorios, naciones, paisajes [...] Sí, hay territorios, sí, hay adhesiones, sí, la cuestión de las fronteras sigue siendo capital, sí, también hay agricultores y paisajes" (Rapin).

Conviene recordar que, desde un punto de vista cultural, el "simbolismo de las zonas espaciales informa o sobredetermina todo otro símbolo material, sea natural, artístico o gráfico" (Cirlot 192), hecho visible incluso en expresiones que se han vuelto cotidianas y que tienen, como sabemos, una carga ideológica importante (relaciones Norte/Sur; Primer Mundo/Tercer Mundo, Centro/Periferia, etc.); e incluso en la abundancia de ideas y conceptos que antes no se expresaban espacialmente y que en la actualidad forman parte habitual del escenario mediático: "conferencia cumbre", "de alto nivel", "línea de conducta", "ruedas de prensa", "sectores sociales", etc. En el mismo sentido, debe subrayarse que entre las imágenes simbólicas la "Gran Madre telúrica" es sin duda " la entidad religiosa y psicológica más universal” (Durand 223), y que en la expresión literaria el eterno femenino y el sentimiento de la naturaleza van indisolublemente unidos, lo que explica no sólo la importancia cultural del espacio sino también otros fenómenos más recientes, como el abierto debate que el "ecofeminismo" inicia en las postrimerías del siglo Xx, advirtiendo en la correlación mujer-tierra un interesante campo teórico cuyo postulado básico puede resumirse en los siguientes términos: que la degradación de la tierra, la destrucción y violación del medio ambiente, el papel irre- 
levante que la naturaleza tiene en la sociedad homocéntrica y su confinamiento utilitario y mercantil a la función reproductiva es una imagen analógica de esas mismas acciones sobre el sujeto femenino.

El debate ecofeminista es sin duda alentador e interesante cuando se entiende, holísticamente, como una práctica que busca "la salvación del cuerpo sagrado de la Tierra" (Gebara 32) y que quiere mostrar no sólo la conexión entre la dominación de las mujeres y de la naturaleza desde el punto de vista de la ideología cultural y de las estructuras sociales, sino introducir también nuevas formas de pensamiento, estimulando lo que ha dado en llamarse "ecojusticia". De acuerdo con la idea de una conciencia global, "en comunión con", que logre reanudar la relación interdependiente entre la naturaleza y el hombre, podrían leerse también las ideas del movimiento "Deep Ecology" ("ecología profunda"), el discurso crítico que Félix Guattari expone en Las tres ecologías (la ecología natural, la ecología social y la ecología mental) y lo que Fritjof Capra denomina "la trama de la vida":

La ecología profunda no separa a los humanos, ni a ninguna otra cosa, del entorno natural. Ve el mundo, no como una colección de objetos aislados, sino como una red de fenómenos fundamentales interconectados e interdependientes. La ecología profunda reconoce el valor intrínseco de todos los seres vivos y ve a los humanos como una mera hebra de la trama de la vida. (Capra 229)

La influencia del medio ambiente en el hombre físico es obvia, pero sus efectos en los estados psíquicos internos, aún siendo menos visibles, son más determinantes y acusados, hecho que puede constatarse en las analogías médicas establecidas por Hipócrates con su clásico tratado sobre la correspondencia entre los humores corporales y las estaciones del año, en la tesis de Posidonius sobre la estrecha relación entre invierno y melancolía, en las estrategias orientales del Feng Shui e incluso en expresiones tan populares y antiguas como "la primavera la sangre altera". De ahí las intuiciones de Carl Jung, para quien el "lugar" constituía un elemento central de la historia de las culturas y las naciones y para el que los 
símbolos espaciales, como el "bosque", resultaron ser significantes universales del inconsciente colectivo, estableciendo incluso las conocidas relaciones de equivalencia entre el carácter extrovertido/introvertido y las posiciones geográficas de Occidente/Oriente. Y de ahí también el pilar filosófico de Heidegger, su sentido del "habitar", su idea de "ser-en-el-espacio, de enraizamiento y pertenencia, porque "habitar" significa estar en un lugar determinado, enraizado en él y pertenecer a él, reconocer, en fin, como dirá Bollnow, que los hombres no existen de modo arbitrario en el mundo, "sino que están ligados a él a través de un vínculo de confianza tal como el que une el alma al cuerpo y el que religa lo expresado con su expresión" (Bollnow 248).

Al hilo de la determinación espacial, como hemos visto, no resultará extraño que en esta encrucijada contemporánea la sensación de pérdida identitaria se acompañe de manifestaciones culturales que tienden a reforzarla y de anuncios que recuerdan, desde ámbitos muy distintos, la necesidad de un proceso integrador, que pueda ajustar las pulsiones regionales y la subjetividad individualidad en el marco uniforme de esta nueva universalización. Las modas étnicas que tanto éxito han tenido en las últimas décadas, los nuevos y más variados cruzamientos socio-culturales (los cholo-punks, los pachuco-krishnas, los ciberaztecas, los rockeros hopi, etc.), la cada vez más creciente conciencia ecológica o los más recientes regionalismos literarios apuntan a este fenómeno, precisamente. Y en este sentido el debate es intenso y no ha hecho más que empezar, porque el fenómeno globalizador y el énfasis regional guardan a su vez una estrecha relación con las apasionantes discusiones culturales que han tomado la escena en las últimas décadas. Los llamados movimientos "post" (postmodernidad, postoccidentalismo, postorientalismo y postcolonialismo) han puesto en juego un proyecto crítico con la modernidad y especialmente con la expansión de un capitalismo sin fronteras que propaga la uniformidad y la estandarización en detrimento de la heterogeneidad. Este proyecto, como bien ha señalado Walter Mignolo desde América Latina, promueve en cambio "la descentralización y la ruptura de la relación entre áreas culturales y producción de conocimientos", contribuyendo "a la restitución de las historias locales como pro- 
ductoras de conocimientos que desafían, sustituyen y desplazan las historias y epistemologías globales" (Mignolo).

En este orden de cosas, es visible que la cultura occidental se enfrenta todavía a las tensiones aún no resueltas entre lo individual y lo social, entre lo singular y lo universal, y que en la justa comprensión del espacio residen no pocas de las claves que aportarán la rica solución a esas fuerzas en apariencia contrapuestas. Y es que si el enfoque posmoderno ha mostrado un énfasis especial en subrayar que las construcciones culturales y la representación son socialmente más determinantes que la propia política, "si se quiere entender el significado de los fenómenos nacionales, étnicos o raciales sólo se tienen que desenmascarar sus representaciones culturales, las imágenes a través de las cuales algunas gentes representan para otros los rasgos de la identidad nacional" (Smith 193). La tarea es compleja, pero también enriquecedora y atractiva, porque se trata de discernir, en una cultura como la nuestra, que se ha elevado sobre los pilares de la representación lingüística, una imagen del mundo superadora de aquellas ilusiones que hemos ido construyendo a través de la semántica. Nada puede decirse de la realidad con independencia del lenguaje que empleamos para hablar de esa misma realidad, porque es obvio que "donde hay código lingüístico hay ideología" (Pániker 286) y que, por tanto, nuestra experiencia espacial asumió en el transcurso de la historia los aditamentos y matices de sus representaciones. Por estas mismas razones es fácil advertir que, como imagen fundacional del universo, el tejido textual del espacio sea, probablemente, el fundamento cultural más decisivo en nuestra percepción del mundo.

Espacio y literatura en Hispanoamérica: apuntes elementales

Ciertamente, nuestra idea del espacio, nuestra imagen de ciudades, países y territorios, está fuertemente condicionada por la cultura y por la influencia directa de los discursos artísticos, generadores de espacios textuales que han sido forjados en la representación literaria y de los que emana una especial "mitología conductora", una imborrable huella psíquica en el conjunto de nuestro imaginario 
colectivo, tal como lo expresara en su día el escritor canario Agustín Espinosa:

La música que salve a un pueblo, a un astro o a una isla, no será nunca música de esta clase. Sino música integral. Sino la creación de una mitología. De un clima poético donde cada pedazo de pueblo, astro o isla, pueda sentarse a repasar heroicidades. Sino aquella literatura que imponga su módulo vivo sobre la tierra inédita. No ha sido de otro modo cómo el mundo ha visto, durante siglos, la India que creó Camoens; o la Grecia que fabricó Homero; o la Roma que hizo Virgilio; o la América que edificó Ercilla; o la España que inventaron nuestros romances viejos.

Una tierra sin tradición fuerte, sin atmósfera poética, sufre la amenaza de un difumino fatal...

Lo que yo he buscado realizar, sobre todo, ha sido esto: un mundo poético; una mitología conductora. (Espinosa 9-10)

El poder cultural del espacio literario es tan denso que a través suyo pueden deducirse múltiples instancias, como ha puesto de relieve en las últimas décadas el campo interdisciplinario de la "ecocrítica" al destacar la interconexión entre el mundo natural y la cultura, tal como se muestra a través de la lengua y la expresión escrita, utilizando para ello interrogaciones tan interesantes como éstas: "¿cómo la naturaleza es representada en este soneto? ¿Son los valores expresados en esta obra consecuentes con la sabiduría ecológica? ¿Cómo nuestras metáforas de la tierra influyen en nuestro modo de tratarla? ¿En qué sentido la misma capacidad de leer y escribir afectó a la relación de la humanidad con el mundo natural? ¿Cómo ha cambiado con el tiempo el concepto de lo salvaje? ¿De qué modo y hasta qué punto el efecto de la crisis medioambiental se está filtrando en la literatura contemporánea y la cultura popular?"(Glotfelty 1996). ${ }^{2}$

2 [How is nature represented in this sonnet? What role does the physical setting play in the plot of this novel? Are the values expressed in this play consistent with ecological wisdom? How do our metaphors of the land influence the 
Por otro lado, es obvio que el espacio literario es el resultado de una operación verbal y de las decisiones tomadas -nunca ingenuamente- en el plano estilístico del texto, y que por tanto es un fenómeno explicable y susceptible de análisis desde el plano morfológico de la obra, el registro más elemental y primario de esa interesante problemática que ha resultado ser la espaciología literaria. Desde esta óptica, pueden reconocerse, por ejemplo, los tópicos espaciales que han sido fijados en el decurso de la tradición literaria, o los patrones culturales de la experiencia del espacio, es decir, esa serie de correlaciones que indican la jerarquía social del mismo (espacios públicos o privados, propios o ajenos, sagrados o profanos) y que son siempre portadores y expresivos de las valoraciones éticas, morales y cosmovisivas establecidas por zonas, provincias, regiones, países e incluso puntos cardinales: "La instancia discursiva del juicio ético se insinúa profundamente en la óptica y la percepción del espacio" (Marchese 316). Las descripciones geográficas, los relatos de viajes o los textos historiográficos como las crónicas de Indias, por ejemplo, pueden darnos múltiples ejemplos de esas valoraciones que, en muchos casos, siguen vigentes aún siglos más tarde de haber sido elaboradas en la lengua escrita, como sucede en la clásica antinomia tan traída y llevada con respecto a Hispanoamérica, "civilización y barbarie", o como se insinúa en nuestros días en algunos populares anuncios publicitarios. ${ }^{3} \mathrm{Y}$ es

way we treat it? How can we characterize nature writing as a genre? In addition to race, class, and gender, should place become a new critical category? Do men write about nature differently than women do? In what ways has literacy itself affected humankind's relationship to the natural world? How has the concept of wilderness changed over time? In what ways and to what effect is the environmental crisis seeping into contemporary literature and popular culture? What view of nature informs U.S. government reports, and what rhetoric enforces this view? What bearing might the science of ecology have on literary studies? How is science itself open to literary analysis?].

3 La campaña publicitaria del licor de coco "Malibú" que se popularizó a través de las pantallas televisivas españolas apela precisamente a estas valoracio-nes ideológicas, manifestando y estimulando a un tiempo el juicio ético tan extendido sobre el Caribe como el territorio del recreo y la parsimonia, donde nada se toma en serio: "Si en el Caribe se tomaran la vida tan en serio no tendríamos Malibú" -concluye textualmente el anuncio-. Más allá del formato cómico de este spot publicitario, su lenguaje forma parte de una imagen estereoti- 
que los territorios literarios nunca son ingenuos, su ideología es siempre intencional, tal como resume acertadamente Lennard Davis: "Todas estas representaciones son ideológicas en el sentido de que llevan incrustados significados sociales. Ningún autor puede recrear realmente un lugar, pero al emplear París o Londres -al igual que Middlemarch o Cumbres Borrascosas- la localización se ve de hecho moldeada por la intersección de la imaginación literaria y la mitología social" (Davis 79). ${ }^{4}$

En el caso concreto del proceso histórico de la literatura hispanoamericana, no cabe duda de que el paisaje fue uno de los elementos más persistentes, y entre los términos que han definido su historia literaria, el "telurismo" adquirió por momentos el rango de piedra angular, hasta convertirse en un reiterado factor de identificación. Ya lo decía Marcelino Menéndez y Pelayo en su célebre Historia de la poesía hispanoamericana al definir la preponderancia de la descripción paisajística como uno de los rasgos representativos del género en Hispanoamérica: "Por eso lo más original de la poesía americana es, en primer lugar, la poesía descriptiva, y en segundo lugar, la poesía política" (16).

Es obvia, por ejemplo, la intensa idealización de América que se desprendió de las crónicas de Indias (El Dorado, el Paraíso), más tarde perpetuada y celebrada en la literatura romántica (aunque con objetivos bien distintos); de otro lado, también es palpable en esos mismos textos inaugurales la demonización de América como escenario natural de la barbarie, extremos ambos que espolearon más tarde los relatos científicos de Humboldt, la polémica defensa de los jesuitas expulsos y las propias tensiones independentistas, haciendo que naturaleza, paisaje y espacio tomaran un valor cultural y político, y que se convirtieran en el soporte semiótico de la identidad americana. Así sucederá en la primera generación de escritores decimonónicos, que anuncian ya los proyectos de la búsqueda de

pada que sigue perpetuándose y que acarrea consigo implicaciones sociales quizás no tan simpáticas.

4 Para enfatizar ese bagaje ideológico del espacio novelesco, Davis distingue entre terreno y escenario frente a "localización intencional" (105), y añade que "Las localizaciones son ideológicas precisamente porque delimitan la acción y encierran sentido aunque sólo aparenten describir con neutralidad" (86-87). 
identidad cultural y literaria a través de un plan visiblemente americanista (Andrés Bello, José Joaquín Olmedo, José María Heredia). El propio Sarmiento, al convertir la ubicación geográfica del $\mathrm{Fa}$ cundo en el eje argumental de la obra, insistirá "en el propósito de Echeverría de hacer de y con el paisaje un tema literario que pueda señalar y denunciar el problema politico" (Area 52). De hecho, "el espacio, la geografía y las territorialidades son parte central de sus tesis sobre América Latina y de su definición de la civilización y la barbarie; es desde el territorio (que no se ha transitado pero que conoce a través de los relatos) que Sarmiento piensa la conformación de la identidad latinoamericana" (Montaldo 69).

El criterio de representatividad del espacio americano resurgirá en el siglo XX a través de distintas corrientes literarias (criollismo, nativismo, regionalismo, indigenismo, negrismo, vanguardismo urbano) generando "la fundación de un sistema de lugares" y la práctica del "nacionalismo geográfico" (Ainsa) cuyas imágenes espaciales aparecen como sustancias portadoras de los contenidos, conflictos y singularidades de la cultura y el ser americanos. Tal como señala Mauricio Ostria, uno de los rasgos principales de la novela hispanoamericana del siglo Xx, más allá de la fiebre regionalista, seguirá siendo la "importancia de los entornos" (Ostria, 1988), la misma que conduce al narrador cubano Alejo Carpentier a definir el proceso del barroco literario trazando una línea de continuidad que avanza desde Bernal Díaz y Hernán Cortés (abrumados por la insuficiencia del lenguaje ante lo "real maravilloso") hasta los autores modernistas -inventores de una poesía "sumamente barroca" -y desde éstos a La Vorágine (1924), Canaima (1935) o la narrativa de Miguel Ángel Asturias. En su recorrido, por cierto, demostrará que ese espíritu barroco, lejos de desaparecer, tiende a intensificarse: "Y lo barroco que ustedes conocen, la novela contemporánea latinoamericana [...] es debida a una generación de novelistas en pie hoy en día, que están produciendo obras que traducen el ámbito americano, tanto ciudadano como de la selva o de los campos, de modo totalmente barroco" (Carpentier 124).

Es interesante observar -aunque no podamos detenernos en este proceso- cómo en la novela hispanoamericana de la segunda mitad del siglo XX, que se presentó a sí misma como superadora 
del regionalismo literario y su estrategia paisajística, la función del espacio cobró un protagonismo radical, tomando desde entonces dos notables direcciones: la primera, una depuración evidente del aparato formal (barroco) del telurismo americano; la segunda, la transformación del espacio desde un mero contexto verbal hacia el verdadero eje estructurante del relato, hechos constatables en las ya célebres novelas de Juan Rulfo y Gabriel García Márquez. ${ }^{5}$

Por lo que respecta a las últimas décadas del siglo XX, y en medio de los procesos posmodernos, el espacio literario seguirá desempeñando un papel estelar, donde destacan procesos tan importantes como la clara "devaluación del concepto de ciudad sin precedentes en la cultura occidental” (Álvarez 16), lo que propicia el desvanecimiento del mito civilizador en favor de un regreso a lo natural. Ello es lo que proyectan las experiencias telúricas del desierto mexicano en un relato como "Coyote" de Juan Villoro; lo que se respira a través de las páginas de Un viejo que leía novelas de amor (1989) de Luis Sepúlveda, epicentro textual de la llamada "novela ecológica"; lo que muestra el tema dominante del encuentro entre el "buen salvaje" y la ciudad de Londres sobre el que Sylvia Iparaguirre fundamenta su exquisita novela La Tierra del fuego (1998); y la sustancia explícita de $W$ aslala. Memorial del futuro (1996), una novela donde Gioconda Belli, con una dimensión acusadora y global, entre el escepticismo posmoderno y la posible utopía, lleva hasta el extremo la devastación ecológica de Latinoamérica, convertida en el basurero de los desechos tecnológicos del Primer Mundo.

Por otra parte, el resurgimiento de las literaturas regionales en las últimas décadas del siglo XX -visibles y especialmente relevantes en países como Chile, Argentina y México- constituye sin duda uno de los fenómenos socioculturales más atractivos e interesantes, en íntima relación con el auge de las periferias en el discurso posmoderno, con la consiguiente descentralización de la cultura y con las lógicas tensiones entre la globalización y el localismo. En el mismo sentido, y en estrecha relación con estos desplazamientos, deben entenderse las discusiones que la literatura fronteriza de México ha suscitado en estos años, pues la escritura chicana en

${ }^{5}$ De este proceso di cuenta en el libro Realismo Mágico y Lo Real Maravilloso: una cuestión de verosimilitud (Llarena 1997). 
Norteamérica desafía con su naturaleza híbrida las antiguas definiciones identitarias, como expresan los personajes de Carlos Fuentes en La frontera de cristal (1995), novela que anuncia sin ambages el nacimiento de sujetos portadores de la nueva espacialidad: "Yo no soy mexicano. Yo no soy gringo. Yo soy chicano. No soy gringo en USA y mexicano en México. Soy chicano en todas partes. No tengo que asimilarme a nada. Tengo mi propia historia" (294). Del lado mexicano, el fenómeno de la llamada "narrativa norteña", del que enseguida vamos a ocuparnos, reafirma de nuevo la profunda alianza entre identidad y espacio, y el rutilante protagonismo que ese vínculo ejerce en el pórtico del nuevo siglo.

\section{El centro está en el Norte: los narradores del norte de México}

No resulta sencillo sintetizar lo que a partir de las últimas décadas del siglo XX ha venido sucediendo en la vida literaria del norte de México. Y es que la actividad cultural y la creación artística han generado en la región, desde los años 80, un espectacular florecimiento de autores y de textos difícilmente reseñables en una visión panorámica. Por otra parte, cuando se habla del norte de México se apunta en general a un espacio geográfico heterogéneo, acentuado por la presencia de los estados fronterizos, con un carácter sociológico más específico; y aún dentro de éstos, el desarrollo económico y cultural de la frontera manifiesta también una visible desigualdad.

En las descripciones crítico-literarias, "frontera" y "desierto" guardan ciertos parentescos y, en realidad, puede decirse que el primero de los nombres es una consecuencia del segundo. Tal como explica Eduardo Antonio Parra, sucede que la prosa del norte de México fue llamada en los años 80 "narrativa del desierto" por la presencia de los accidentes geográficos en sus autores estelares, fundadores entonces de una tradición regional: Jesús Gardea (Chihuahua), Gerardo Cornejo (Sonora), Ricardo Elizondo (Nuevo León), Severino Salazar (Zacatecas) y Daniel Sada (Mexicali). ${ }^{6}$ Sin 
embargo, el término resultaría insuficiente para designar a otros escritores norteños cuya temática apuntaba en otras direcciones, de ahí la sustitución por el de "narrativa fronteriza", el más extendido hasta la fecha, no sin ciertos debates (Parra 5).

En un artículo titulado "De ciertos desiertos inciertos", el poeta, narrador y ensayista Alfredo Espinoza, describe el valor identitario que el desierto alcanzó en el nuevo regionalismo mexicano de Chihuahua ("Y por los años ochenta los chihuahuenses nos enamoramos de nosotros mismos. Y el desierto fue nuestro espejo"), señalando que fue éste, sin duda, el paisaje con mayor presencia entre los norteños, el que logró erigirse en el significante simbólico de la zona ("el desierto pulía nuestros rasgos, explicaba nuestra palabra austera, torpe, franca y agresiva") y el motivo estético y literario a través del cual, en definitiva, los chihuahuenses exacerbaron su singularidad, reclamando el respeto y la atención a sus señas peculiares; exigencia, por cierto, que a su juicio no pretendía una confrontación excluyente con el resto de la identidad nacional ni una desmembración de la mexicanidad, sino un deseo de contribuir a un nuevo concepto de nacionalidad: "se decía en aquellos candorosos días que habría que chihuahuenizar el país" (Espinoza). ${ }^{7}$ Es en este contexto donde se inscribe la obra narrativa de Jesús Gardea (1939-2000), a quien hoy se considera un máximo exponente de la "narrativa del desierto". Autor de obras ya imprescindibles en el panorama nacional y reconocido como uno de los valores de la escritura mexicana con proyección internacional, su fundación imaginaria de "Placeres" (el lugar donde transcurren sus ficciones, trasunto literario de Delicias, su localidad de origen, como él mismo confesaría) y la temática y el estilo de su prosa le

do las poblaciones de Coahuila. En la conformación de esta misma tradición literaria no deben olvidarse, por otro lado, los Cuentos del Desierto (1959) de Emma Dolujanoff, cuya materia artística incorpora los aspectos mágicos y legendarios de sus poblaciones indígenas.

7 Él mismo contribuirá al nuevo regionalismo de Chihuahua con su novela Infierno grande (1990), los poemarios Desfiladero (1991) y Tatuar el humo (Premio Nacional de poesía "Gilberto Owen" 1992) y sus ensayos sobre la cultura del norte mexicano. Junto al poeta Rubén Mejía fue el coautor de la Muestra de la poesia chibuabuense 1976-1986 (1986). 
han deparado no pocas -y en absoluto gratuitas- comparaciones con Juan Rulfo.

Pero si el desierto constituyó en los años ochenta la incorporación estable del escenario norteño a la literatura nacional, revelando la singularidad de sus paisajes y la materia artística de sus ritmos de vida, su expresión y sus costumbres, el conjunto de la llamada literatura fronteriza fortaleció definitivamente esta presencia, visibilizando la frontera como una región cultural específica cuya personalidad histórica y sociológica le han conferido su propia identidad. En territorio mexicano, su estudio empezó a mediados de los ochenta, en parte por la preocupación del "centro" "por reforzar el fardo romántico de la identidad" (Luna 79), por "cultivar y nacionalizar a los estados fronterizos, dándose a conocer lo que consideró la esencia de lo mexicano" (Conde 52).

De este modo fue configurándose una escritura que ha servido para reafirmar el sentido regional, para reconocerse en lo local, y que "ha dado más que cualquier otro icono autenticidad y legitimidad a nuestro Ser norteño. Ha delineado nuestra geografía, nuestro espacio y nos ha heredado historicidad, tiempo y ubicuidad" (Luna 81). Y es que, en efecto, en la década del ochenta todos compartieron una misma preocupación, el tema regional de "lo fronterizo", en un momento histórico en el que el concepto de Nación se enfrentaba a un proceso de "disemiNación" (Bhabha). En esa misma eclosión del tema fronterizo y en la evidente actualidad de la que goza en nuestros días, debe interpretarse la seducción y el interés que ha despertado en autores que no sólo no pertenecen a la zona, sino que rebasan incluso el ámbito nacional: es el caso de Carlos Fuentes (La frontera de cristal. Una novela en nueve cuentos, 1995) y del escritor español Arturo Pérez Reverte (La reina del Sur, 2002).

Vista desde una perspectiva panorámica, el predominio en la literatura norteña le corresponde todavía a la narrativa y la poesía, frente al desarrollo más escaso del teatro y del ensayo. Y en cuanto a los temas, y en los dos géneros más constantes, el consenso es evidente: la realidad geográfica (sierra, mar, desierto, ciudades, o la frontera misma) es fundamental, espacios que se construyen en un lenguaje de tendencia coloquial y vernácula, con una fuerte contaminación anglosajona, y que muestra la realidad específica de la zona. Igualmente, entre los rasgos generales debe notarse el pre- 
dominio de la recreación de la cotidianidad (sin caer en el costumbrismo provinciano) y la representación del espacio urbano, soportes temáticos sobre los que la escritura fronteriza contesta hoy a las imágenes heredadas de la tradición: entre ellas, la de un lugar de fácil penetración cultural, ya sea por medio del lenguaje, las costumbres o el estilo de vida producto del contacto inmediato con los Estados Unidos, o su percepción como "border of fear/border of desire" (Romero), o como la antigua y deshabitada tierra de nadie.

En el caso concreto de la literatura bajacaliforniana, la ruptura con el aislacionismo cultural y la integración de la península al contexto cultural nacional tuvo un pilar importante en los años sesenta en el llamado movimiento de "La Californidad", que a modo de cruzada cultural se propuso dotar a Baja California de tradición y memoria histórica. La novela Calle Revolución (1964) de Rubén Vizcaíno Valencia constituyó una de las expresiones novelísticas más importantes y polémicas del movimiento, en tanto fundación simbólica y mítica de un espacio vicioso y depravado, la ciudad de Tijuana, presentada en la obra como la ciudad de los pecados capitales. A partir de ella, las imágenes de la urbe empiezan a aflorar convirtiendo a la Avenida Revolución, centro neurálgico de Tijuana, en escenario de una gran cantidad de textos bajacalifornianos: Vizcaíno lo hará de nuevo en Tijuana Go-Go (1967); Federico Campbell en Tijuanenses (1989); Roberto Castillo Udiarte en Blues cola de lagarto (1987), Cartografías del alma (1987), Nuestras vidas son otras (1994), y La pasión de Angélica según el Jonnhy Tecate (1996); Rosina Conde en El agente secreto (1990) y Arrieras somos (1994); Martín Romero en Comicópolis (1999); o Luis Humberto Crosthwaite en Marcela y el Rey al fin juntos (1988) y Estrella de la Calle Sexta (2000).

Debe saberse al respecto que la ciudad bajacaliforniana es la frontera con mayor tránsito del mundo, la más importante como puente de paso hacia los Estados Unidos en territorio mexicano, atravesada a diario por cuatrocientas mil personas en ambas direcciones y que, desde sus primeras etapas de desarrollo durante los años treinta, Tijuana se alineó en torno a la calle Revolución, poblándose de bares, hoteles y restaurantes, casas de juego y prostíbulos, por lo que se convirtió en el eje del diseño urbano posterior. En este sentido, la avenida Revolución es hoy la vía citadina más 
importante del noroeste mexicano, una pieza clave para estudiar la naturaleza y evolución de la identidad fronteriza. Es así como la ciudad más visitada del mundo, a la que Néstor García Canclini ha definido como el "laboratorio de la posmodernidad" (Canclini 293), recibe en la escritura su propia "mitología conductora", construcciones simbólicas que no sólo le otorgarán protagonismo sino también un aura luminosa, redimiendo a la ciudad de los vicios de sus antiguas vestiduras identitarias. En este orden de cosas, no es extraño que, del mismo modo en que se habló de la necesidad de chihuahuenizar el país, Federico Campbell considere la "tijuanización" de México como el fenómeno cultural de los años noventa, tal como expone en Máscara negra (1995), que reúne sus artículos publicados en el diario La Jornada desde 1989 a 1993, y en los que hay afortunadas recurrencias temáticas en torno a todo tipo de expresiones culturales fronterizas.

Desde un punto de vista literario, los novelistas de la península californiana manejan los recursos generales de la novela contemporánea haciendo uso de una rica y compleja intertextualidad entre los patrones culturales de la tradición mexicana y europea, e incorporando materiales norteamericanos de la alta cultura y de la cultura popular (desde el cine al rock, desde la televisión al blues, desde el video a la cibercultura). Con un lenguaje poblado de expresiones cultas y hablas locales o personales, en busca de su propia identidad, es visible la pugna entre la expresión regional y cosmopolita, forcejeo en el que la presencia del spanglish es notoria e ineludible. Destaca además la hibridación genérica (narrativa, poesía-crónica, testimonial, narrativa, viñetas sociales, costumbristas, contestatarias, intimistas...) y el aprovechamiento de las innovaciones estéticas aplicadas a un contexto regional y periférico, donde abundan las expresiones culturales marginales y alternativas (lo gay y el lumpen, entre otras) y las manifestaciones de la cultura popular norteña, que tendrá un bastión aventajado en la música regional; no en vano, el curioso fenómeno de los "narcocorridos" - con la fama internacional de la que en estos momentos gozan grupos tan conocidos como "Los Tigres del Norte"- apunta precisamente a esa épica regional que se construye con la realidad sociocultural de la zona, y de la que dan buena cuenta algunos de los autores más relevantes del panorama fronterizo. Sucede así, por ejemplo, en la 
lúdica escritura de Luis Humberto Crosthwaite, quien en su novela Idos de la mente. La increíble y (a veces) triste historia de Ramón y Cornelio (2001) rinde homenaje a la tradición musical norteña. A finales de 2002, este mismo escritor ofició de conferenciante en la ciudad de Barcelona con un texto titulado "Misa fronteriza (Cowboys vs. Mariachis: música y cultura en la frontera norte de México)" para dar cuenta del maridaje cultural que propicia la vivencia fronteriza, de la que se considera abiertamente representante. He aquí, a modo de conclusión, algunos de los fragmentos que bien podrían resumir lo que hemos señalado a lo largo de esta páginas:

Mi nombre es Luisumberto y soy fronterizo.

Me declaro así, abiertamente, sin pena ni gloria.

Confieso ante ustedes que mi religión es la frontera. Monotemático, me dicen. Aburro y divierto al mejor de los escuchas. Proclamo en las esquinas de las calles más transitadas, en las cantinas, en los centros culturales la Buena Nueva de esta franja que me atraviesa el cuerpo como atraviesa al mundo. Estoy biseccionado entre dos países y dos culturas, me declaro triunfador y derrotado en la guerra de los cowboys contra los mariachis.

$[\ldots]$

Mi nombre es Luisumberto y mi religión es la frontera. No se dejen engañar: soy más alto de lo que parezco, menos bruto, más miope, mejor esposo, peor amante, enaltecido padre de familia, ridículo comediante de palabras. Estoy ante ustedes, tal como soy, biseccionado, dividido entre el aquí y el allá. ¿Les dije que estoy biseccionado? ¿Quieren que les muestre mi bisección? Atraviesa mi alma de un extremo a otro. Es la frontera, brother, la traigo tatuada en el brazo; la frontera, beibi, la llevo atravesada en el pescuezo; la frontera, míster, se me ha metido al corazón y ahí está clavada. Y ahí es donde la quiero. 
En el principio fue José Alfredo Jiménez. Pero José Alfredo nunca se imaginó que en el norte de México; o sea, en el Sur de Estados Unidos, se fraguaba un mestizaje, y de ese mestizaje brotaría un sonido nuevo.

Bendita sea por siempre nuestra música.

El acordeón nos llegó de Texas y el bajo sexto nos llegó del sur mexicano. Ya existían desde hace mucho, pero fue ahí, en la frontera, donde se conocieron, se enamoraron y se pusieron a cantar.

Bendita sea por siempre nuestra música. ${ }^{8}$

\section{Bibliografía}

Ainsa, Fernando. Identidad cultural de Iberoamérica en su narrativa. Madrid: Gredos, 1986

Álvarez-Tabío, Enma. Invención de La Habana, Barcelona: Casiopea, 2000.

Area, Lelia. "El Facundo de Sarmiento o las políticas del paisaje." Estudios 5 (1995): xx-xx

Bhabha, Homi. "DissemiNation." Nation and Narration. Ed. Homi Bhabha. Londres: Routledge, 1990. 291-322.

Bollnow, Otto Friedrich. Hombre y espacio. Barcelona: Labor, 1969.

Capra, Fritjof . La trama de la vida. Barcelona: Anagrama, 1999.

Carpentier, Alejo. "Lo barroco y lo real maravilloso." Razón de Ser. Ensayos. La Habana: Letras Cubanas, 1984.

Cirlot, Juan Eduardo. Diccionario de símbolos. Barcelona: Labor, 1988.

Conde, Rosina. “¿Dónde está la frontera?” El Acordeón 7 (1992).

8 El texto "Misa fronteriza (Cowboys vs. Mariachis: música y cultura en la frontera norte de México)" de Luis Humberto Crosthwaite, fue leído como conferencia en Barcelona en diciembre de 2002. Agradezco infinitamente a Luis Humberto la gentileza de su envío. (Disponible ya en Internet. N. del E.) 
Crosthwaite, Luis Humberto. Idos de la mente. La increíble y (a veces) triste historia de Ramón y Cornelio. México: Joaquín Mortiz, 2001.

Crosthwaite, Luis Humberto. "Misa fronteriza (Cowboys vs. Mariachis: música y cultura en la frontera norte de México)." Barcelona, 2002. <http:/www.elmalpensante.com/47_feria.asp>.

D’ors, Víctor. "Prólogo recensional." Hombre y espacio de O. Friedrich Bollnow. Barcelona: Labor, 1969.

Davis, Lennard J. Resistirse a la novela. Novelas para resistir. Ideologia y ficción. Barcelona: Debate, 2002.

Durand, Gilbert. Las estructuras antropológicas de lo imaginario. Madrid: Taurus, 1979.

Espinosa, Agustín. Lancelot $28^{\circ} 7^{\circ}$. Tenerife: Interinsular Canaria, 1988.

Espinoza, Alfredo. "De ciertos desiertos inciertos." Fronteras (Revista de diálogo cultural entre las fronteras de México). $<$ http:/www.cnca.gob.mx/cnca/buena/descentra//cnd/frontera /htm/inciertos.html>.

Fuentes, Carlos. La frontera de cristal. Una novela en nueve cuentos. Madrid: Alfaguara, 1995.

García Canclini, Néstor. Culturas híbridas. Estrategias para entrary salir de la modernidad. México: Grijalbo, 1990.

Gebara, Ivone. Intuiciones ecofeministas. Ensayo para repensar el conocimiento y la religión. Madrid: Trotta, 2000.

Glotfelty, Cheryll. "Introduction: Literary Studies in an Age of Environmental Crisis." The Ecocriticism Reader: Landmarks in Literary Ecology. Eds. Cheryll Glotfelty and Harold Fromm. Athens, Georgia: University of Georgia Press, 1996.

Gould, Peter. "Pensamientos sobre la geografía." Geocrítica 68 (1987): 1-42. <http://www.ub.es/geocrit/geo68.html>.

Luna, Francisco. "Visiones fronterizas." Literatura fronteriza de acá y de allá. Memorias del encuentro binacional "Ensayo sobre la literature de las fronteras." Comp. Guadalupe Beatriz Aldaco, comp. México: Instituto Sonorense de Cultura y Consejo Nacional para la Cultura y las Artes, 1994. 79-84.

Lutwack, Leonard. The Role of Place in Literatura. Syracuse: Syracuse University Press, 1984.

Llarena, Alicia. Realismo Mágico y Lo Real Maravilloso: una cuestión de verosimilitud. Gaithersburgh: Ediciones Hispamérica, 1997. 
Marchese, Angelo. "Las estructuras espaciales del relato." La narratología hoy. La Habana: Arte y Literatura, 1989.

Menéndesz Pelayo, Marcelino. Historia de la poesía bispanoamericana. Madrid: Librería de Victoriano Suárez, 1911.

Mignolo, Walter. "Postoccidentalismo: el argumento desde América latina." Teorias sin disciplina (latinoamericanismo, poscolonialidad y globalización en debate). Eds. Santiago Castro-Gómez y Eduardo Mendieta. México: Porrúa, 1988. < http//ensayo.rom.uga.edu/ critica/teoria/castro/mignolo.htm>

Montaldo, Graciela. Ficciones culturales y fábulas de identidad en América Latina. Rosario Beatriz Viterbo, 1999.

Ostria, Mauricio. "Notas sobre la importancia de los entornos en la literatura hispanoamericana." Escritos de varia lección. Chile: Sur, 1988.

Pániker, Salvador. Aproximación al origen. Barcelona: Kairós, 2001.

Parra, Eduardo Antonio. "Notas sobre la nueva narrativa del norte." Jornada Semanal 27 de mayo, 2001.

Rapin, Anne. "El sentido de la memoria" (entrevista a Alain Finkielkraut). Label France 38, 2000. < http:/www.frence.diplomatie. fr/label_france/ESPANOL/DOSSIER/2000/02heritage.html>.

Romero, Rolando. "Border of Fear, Border of Desire." Borderlines. Studies in American Culture 1 (1993): 36-70.

Smith, Anthony D. “¿Gastronomía o geología? El rol del nacionalismo en la reconstrucción de las naciones." La invención de la nación. Lecturas de Herder a Homi Bhabh. Comp. Álvaro Fernández Bravo. Buenos Aires: Manantial, 2000.

Villanueva Zarazaga, José. "Algunos rasgos de la geografia actual." Biblio 3W, Revista Bibliográfica de Geografía y Ciencias Sociales 342. $<$ http:/www.ub.es/geocritb3w-342.htm>

Weil, Simone. Echar raices. Madrid: Trotta, 1996. 
